\title{
Working conditions and job satisfaction of Argentinian psychiatrists: initial results of a comprehensive survey
}

\author{
Elsa Wolfberg ${ }^{1}$ MD and Daniel Moldavsky² MD DipPsych
}

'Associate Professor of Clinical Psychiatry, Faculty of Medicine, University of Buenos Aires, and Head of the Faculty of Prevention in Psychiatry, Association of Argentinian Psychiatrists, Argentina; ${ }^{2}$ Consultant Psychiatrist, Nottinghamshire Healthcare NHS Trust, Kings Mill Hospital, Sutton-in-Ashfield, Nottinghamshire, UK, email daniel.moldavsky@nottshc.nhs.uk

W orking in psychiatry is generally rewarding. However, it can also lack job satisfaction and be detrimental to personal life. Research findings indicate high rates of burnout (Kumar et al, 2007), impaired health status of practitioners (Korkeila et al, 2003), negative effects of violence in the workplace (Inoue et al, 2006) and lack of job satisfaction (Fischer et al, 2007; Bressi et al, 2009).

This article presents the initial results of a survey performed by the Association of Argentinian Psychiatrists (APSA in Spanish) at its 25th annual meeting in 2009. The survey was planned in a series of discussions and workshops on working conditions and professional burnout (Wolfberg, 2003). These discussions followed the economic crisis of 2001, when Argentina's financial and economic system collapsed. It was then that the APSA's executive committee commissioned a comprehensive survey of psychiatrists' working conditions, health status and related topics. Its objectives were to collect initial data from psychiatrists, with the aim of delineating areas for future research.

We report in this article the results obtained on working conditions, job satisfaction and doctors' perceptions of the support available to them in their workplace.

\section{Methods}

\section{Sample}

A structured interview was offered to all doctors attending the 25th annual meeting of the APSA, held 21-24 April 2009, at Mar del Plata, Argentina. Participants' consent was obtained before the interview, including their agreement to disseminate the results on the Association's website and in publications. The survey had ethical approval from the APSA.

\section{Data collection and analysis}

The questionnaire for the interview was designed by members of APSA's Faculty of Prevention in Psychiatry. The Faculty is chaired by the first author of this paper (EW). The interviews were carried out by ten psychology students previously trained by EW.

The questionnaire was designed to obtain the information in a user-friendly and culturally sensitive manner. It included several domains:

work location and conditions

total income (often combined earnings from more than one source)
○ job satisfaction

O supervision at work (most psychiatrists in Argentina, including senior professionals, work with a psychotherapeutic orientation and supervision is embedded into the job)

o sources of recognition at work

O violence at work

O health status

work-life balance.

\section{Results}

The sample consisted of 722 participants (55.4\% female, $44.6 \%$ male). The participation rate was $82 \%$. The mean age of participants was 47 . For some of the data analysis, the sample was divided into three age groups, as follows:

o those under 30 years ( $n=89,12.3 \%$ of the sample)

those between 30 and 50 years $(n=337,46.7 \%)$

O those older than $50(n=296,41.0 \%)$.

The mean time since qualification in the total sample was 19.5 years. Most (84.9\%) were qualified specialists; the remainder $(15.1 \%)$ were trainees. Marital status was as follows: $51.0 \%$ married, $8.3 \%$ cohabiting, $2.5 \%$ widowed, $20.1 \%$ single and $18.1 \%$ divorced.

Income was divided into three bands (in Argentine pesos): O low, for those who reported earnings less than ARS3000

o middle, for those earning ARS3000-7000

O high, for those earning more than ARS7000.

Only $2.2 \%$ of young doctors (aged 30 or under) reported having an income within the high band, while $63.0 \%$ were within the low band. Of doctors in the middle age group (30-50 years), 50.2\% reported having an income within the middle band and $29.1 \%$ in the high band. Even among doctors aged more than $50,8.8 \%$ were still within the lowincome band and $53.7 \%$ reported their income within the middle band. However, income was reported as being sufficient to meet doctors' needs by $67.4 \%$ of young doctors, by $76.3 \%$ of doctors in the middle age group and by $79.7 \%$ of those aged more than 50 .

More than half of the doctors surveyed reported working 31-50 hours weekly in each of the age groups. However, a substantial number of doctors worked more than 50 hours: $14.6 \%$ of young doctors, $29.3 \%$ of doctors in the middle age group and $24.6 \%$ of those aged more than 50 . Data for working hours did not include the on-call shifts for those who were in hospital practice. 
Table 1 Select survey results, by age group (\% of respondents)

\begin{tabular}{|c|c|c|c|}
\hline & $<30$ years $(n=89)$ & $30-50$ years $(n=337)$ & $>50$ years $(n=296)$ \\
\hline Satisfaction with job & 90 & 91 & 92 \\
\hline Satisfaction with time for patients & 47 & 67 & 80 \\
\hline Satisfaction with time for supervision & 67 & 45 & 32 \\
\hline Exposure to violence at work & 86 & 81 & 69 \\
\hline \multicolumn{4}{|l|}{ Perceived recognition in the workplace } \\
\hline from patients & 73.6 & 75.0 & 68.1 \\
\hline from colleagues & 47.2 & 46.9 & 52.4 \\
\hline from medical directors & 21.3 & 29.4 & 29.7 \\
\hline no recognition & 5.6 & 5.9 & 6.1 \\
\hline not reported & 19.1 & 13.1 & 11.8 \\
\hline \multicolumn{4}{|l|}{ Employment, by sector } \\
\hline private practice only & 21.3 & 28.5 & 40.6 \\
\hline public sector only & 36.0 & 13.1 & 6.1 \\
\hline public and private combined & 13.5 & 24.6 & 19.9 \\
\hline HMO only & 10.0 & 7.1 & 8.4 \\
\hline $\mathrm{HMO}$ and private and public practice & 4.5 & 9.2 & 6.4 \\
\hline HMO and public practice & 7.9 & 2.7 & 1.4 \\
\hline $\mathrm{HMO}$ and private practice & 6.7 & 14.8 & 17.2 \\
\hline
\end{tabular}

HMO, health maintenance organisation.

Doctors in Argentina usually work in several settings: public sector hospitals, private practice and health maintenance organisations (HMOs), which deliver insurance-based healthcare. More than a quarter of doctors in the middle and older age groups reported working in private practice only.

Table 1 shows data on perceived job satisfaction, including satisfaction with supervision at work, and the results regarding perceived recognition in the workplace.

\section{Discussion}

The survey was the first ever performed in Argentina about working conditions for psychiatrists. Despite the presence of a psychiatric system in the country since the beginning of the 20th century, both political upheavals and the lack of organisation of the medical profession delayed the establishment of an inclusive psychiatric association until the restoration of democracy in 1983. The APSA is the first society to represent members in Argentina and those Argentinians living and working abroad.

A persistent lack of funds has hindered the development of approaches more consistent with systematic research and evidence-based psychiatry. In this context, we think this survey constitutes a first attempt to gather data; the results should illuminate areas for further research.

One remarkable finding of this survey is that perceived satisfaction with work remains high for all age groups of professionals surveyed, with more than $90 \%$ of doctors declaring satisfaction with their jobs. Studies on the subject in Latin America more widely are few. One article reported a similar survey to ours in Colombia; it found a rate of job satisfaction of $71 \%$ among those surveyed (Gomez-Restrepo et al, 2003). In the present survey, satisfaction with time available for patients seemed to correlate with age, with young doctors declaring less satisfaction in this respect. Conversely, more young doctors declared their satisfaction with the arrangements for supervision.

At present, many doctors in Argentina hold several jobs within the private and public sectors, and work long hours to achieve a reasonable standard of living. More than a quarter of doctors surveyed worked in private practice. The percentage of those working exclusively in private practice increased with age (Table 1). Still, about a third of doctors worked for several employers, in a combination of various sectors (public, HMOs and private practice). Although jobs in the public sector are poorly paid, if not unpaid, they do constitute the main route to the acquisition of specialist qualifications; it is therefore not entirely surprising that the only way to make financial progress is to move from the public to the private sector. For those who do progress, earnings nonetheless remain low when compared with those in high-income countries. A conversion of the local currency (ARS) to British pounds should really account for the instability of the Argentine currency, due to persistent inflation. However, if taking a mean value of $f 1=A R S 6$, incomes will be equivalent to up to $f 500$ monthly for the low-income group, f500-1170 monthly for the middle-income group, and more than $f 1170$ monthly for the high-income group. These figures are objectively low for Argentina, a country undergoing a process of globalisation, which leads to, among other things, a constant sharp increase in the prices of basic commodities. Nevertheless, about three-quarters of doctors surveyed declared their incomes to be sufficient to meet their needs. Again, more rigorous investigation is required, including a more accurate operational definition of needs.

In this context, it is remarkable that $90 \%$ or more of those surveyed declared a subjective sense of satisfaction with the profession. To our knowledge, the only survey done in 19 Latin American countries (including Argentina) reported similar rates of job satisfaction (86.4\%), but there was a lower rate of satisfaction with incomes (only $64.7 \%$ ) (Cordoba et al, 2009).

This survey has several domains that merit future research. It will be interesting to develop a more sophisticated approach to assess job satisfaction. It could be assessed on several domains of the clinical work. Variable rates were reported across the three age groups on satisfaction with time for supervision. The presence and quality of supervision have been found by others to be significantly associated with job satisfaction for both trainees (Ellencweig et al, 2009) and specialists (Kazantzis et al, 2010). 
Doctors reported patients and colleagues to be their main sources of recognition in the workplace. We hypothesise that perceived recognition increases self-esteem and provides emotional support, which may, in turn, compensate for the low financial recognition. Psychiatry has historically been a prestigious specialty in Argentina. It will be interesting to test formally the hypothesis whether its prestige is related to the subjective satisfaction of practitioners.

A study evaluating job burnout in a European Union country used several structured assessments. It found that that a low level of job satisfaction was the variable that most predicted burnout (Bressi et al, 2009). Our group is currently researching to what extent burnout is predicted by emotional exhaustion, as opposed to lack of job satisfaction (Wolfberg et al, 2005).

In summary, this study was the first to have addressed in Argentina questions about psychiatrists' job satisfaction and related aspects of their working lives. It surveyed a large sample, and provided data to advance research, in a country rich in human resources, and a system that needs a more rigorous research policy.

\section{Acknowledgements}

The authors deeply thank all members of the Faculty of Prevention in Psychiatry, Association of Argentinian Psychiatrists, who took an active part in this project.

\section{References}

Bressi, C., Porcellana, M., Gambini, O., et al (2009) Burnout among psychiatrists in Milan: a multicenter survey. Psychiatric Services, 60, 985-988.

Cordoba, R. N., Cano, J. F., Alzate, M., et al (2009) [The Latin American psychiatrist: profile and degree of satisfaction with the specialty.] Actas Españolas de Psiquiatría, 37, 9-16.

Ellencweig, N., Weizman, A. \& Fischel, T. (2009) Factors determining satisfaction in psychiatry training in Israel. Academic Psychiatry, 33, 169-173.

Fischer, J., Kumar, S. \& Hatcher, S. (2007) What makes psychiatry such a stressful profession? A qualitative study. Australasian Psychiatry, 15, 417-421.

Gomez-Restrepo, C., Gil Laverde, F., Diaz-Granados, N., et al (2003) El perfil del medico psiquiatra colombiano. [Stereotype of the Colombian psychiatrist.] Revista Colombiana de Psiquiatría, 32, 325-340.

Inoue, M., Tsukano, K., Muraoka, M., et al (2006) Psychological impact of verbal abuse and violence by patients on nurses working in psychiatric departments. Psychiatry and Clinical Neurosciences, 60, 29-36.

Kazantzis, N., Calvert, S. J., Orlinsky, D. E., et al (2010) Professional development perceptions and activities of psychiatrists and mental health nurses in New Zealand. New Zealand Medical Journal, 123, 24-34.

Korkeila, J. A., Toyry, S., Kumpulainen, K., et al (2003) Burnout and selfperceived health among Finnish psychiatrists and child psychiatrists: a national survey. Scandinavian Journal of Public Health, 31, 85-91.

Kumar, S., Fischer, J., Robinson, E., et al (2007) Burnout and job satisfaction in New Zealand psychiatrists: a national study. International Journal of Social Psychiatry, 53, 306-316.

Wolfberg, E. (2003) [Social crisis and occupational fatigue among health professionals: warnings and resources.] Vertex, 14, 268-279.

Wolfberg, E., Heumann, G., Mazzella, L., et al (2005) [Problems and resources among hospital physicians, residents, and nurses in their hospital work.] Vertex, 16, 5-12.

\section{Training on the management of depression in primary care in Azerbaijan}

\section{Fuad Ismayilov' and Sevil Asadova ${ }^{2}$}

1'Department of Psychiatry, Azerbaijan Medical University, email fuadismayilov@psychiatry.az; ${ }^{2}$ World Health Organization, Country Office, email AsadovaS@euro.who.int

n 2006, the Azerbaijan Ministry of Health and the World Bank launched the 6-year Health Sector Reform Project (HSRP). The principal goal of the Project is to prepare and implement a fundamental and comprehensive reform of the health system in Azerbaijan, including a major emphasis on strengthening the primary care system (Ministry of Health Project Implementation Unit, 2007). The project envisions the development of a new optimised system of services, with the integration of mental health into general healthcare. In the line of this process, the Public Health and Reform Centre (PHRC) of the Ministry of Health has developed evidence-based clinical practice guidelines on depression, for implementation within primary care (Ministry of Health, 2009). At the same time, representatives from the PHRC and the Departments of Psychiatry and Family Medicine of Azerbaijan Medical University, as well as the State Institute for Advanced Training of Physicians (in cooperation with the World Health Organization Country Office), formed a task force to carry out a survey to assess the need for education in mental health for primary care doctors. A total of 308 primary care doctors (see Table 1) working in 14 settings in different regions of the country were randomly selected and interviewed by the research team.

All participants of the survey were asked to fill in a specially designed semi-structured questionnaire consisting of 34 items. Along with items covering personal information and professional responsibilities, the questionnaire included a set of questions about the recognition and treatment of depression in primary care. In addition, it queried the respondents' opinions and expectations regarding improvements in care provision for patients with depression. 